\title{
Post-Keynesian macrodynamics and path-dependent growth
}

\author{
Mark Setterfield ${ }^{*}$
}

\begin{abstract}
This paper discusses the treatment of growth as a path-dependent process in post-Keynesian macrodynamics. A synthetic post-Keynesian growth model is used to demonstrate the ways in which growth can be described as pathdependent in the post-Keynesian tradition. Recent developments in neoclassical endogenous growth theory are then discussed, with a view to highlighting the sense in which these developments encroach on the post-Keynesian treatment of growth as demand-led and path-dependent. Finally, the paper reflects on the pros and cons of these neoclassical developments for the future of post-Keynesian macrodynamics.

JEL classifications: $E_{I 2}, E_{I 3}, O_{4 I}$

Keywords: post-Keynesian growth theory, neoclassical growth theory, endogenous growth, path dependence
\end{abstract}

\section{Introduction}

The importance of historical time is a long-standing theme in post-Keynesian economics. An important part of post-Keynesians' concern with historical time is the notion that earlier states of the world generate later ones. Specifically, rather than tending inexorably towards states that are determined independently of the adjustment path taken towards them, economic

* Trinity College, Hartford/CT, USA. An earlier version of this paper was presented at the Recent Developments in Post-Keynesian Modelling conference held at the University of Paris XIII, November 20-2I, 2009. I am grateful to conference participants, Claude Gnos, Dominique Plihon and two anonymous referees for their helpful comments. Any remaining errors are my own.

Correspondence Address:

Mark Setterfield, Department of Economics, Trinity College, Hartford, CT, o6ro6 USA, e-mail: mark. setterfield@trincoll.edu.

Received Io December 2009, accepted 6 October 2010

(C) INTERVENTION 8 (2), 2OII, 299-3I6 
outcomes - including anything that can be construed as slong-run are understood to display some form of path dependence.

The focus of this paper is on the path dependence of growth outcomes in post-Keynesian macrodynamics. Specifically, the paper discusses the substance of post-Keynesian claims to model growth as a path-dependent process. It also draws attention to recent developments in neoclassical endogenous growth theory that encroach on this terrain, and reflects on the ramifications of these developments for the future of post-Keynesian macrodynamics.

The remainder of the paper is organised as follows: Section 2 considers the meaning of endogenous growth in post-Keynesian macrodynamics, and in particular the sense in which endogenous growth can be associated with path-dependent growth. Section 3 then illustrates the ways in which the growth process is understood to display path dependence in post-Keynesian macrodynamics. In Section 4, some recent developments in neoclassical endogenous growth theory are highlighted. Attention is drawn to the sense in which these developments encroach on the post-Keynesian treatment of growth as a demand-led and path-dependent process. Section 5 then considers some of the opportunities and challenges that these neoclassical developments present for post-Keynesian macrodynamics. Finally, section 6 concludes.

\section{Endogenous growth as path-dependent growth}

In the lexicon of contemporary macroeconomics, the term sendogenous growth is widely used to describe the properties of a class of neoclassical growth models that have been developed over the past 25 years, and that trace their origins to the work of Romer (1986 and 1990) and Lucas (1988). But this proprietorial use of the term sendogenous growth represents nothing more substantial than the neoclassical `capture of the terminology of growth theory (on which, see Roberts/Setterfield 2007). As a matter of fact, post-Keynesian macrodynamics has long featured models in which growth is endogenous in the sense that either:

a) technical change is explicitly modelled; and/or

b) the growth rate emerges from the (equilibrium) solution of the model, and is amenable to change by economic decision makers (public or private).

Either or both of these basic features of endogenous growth are clearly evident in the contemporary canonical Kaleckian and Kaldorian growth models with which post-Keynesian macrodynamics is chiefly associated. ${ }^{\mathrm{I}}$

Moreover, post-Keynesian macrodynamics has long been committed to a conception of endogenous growth that is ideeper than that suggested by either of the two characteristics listed above. According to this deeper conception, growth is endogenous in the sense that

I See, for example, Lavoie (1992, ch. 6), Blecker (2002), McCombie and Thirlwall (1994, ch. 3) and Setterfield (1997, ch.3) for expositions of the canonical Kaleckian and Kaldorian models of growth referred to above. 
the growth rate today is sensitive to the pace of growth established in the past. In other words, growth is endogenous to its own past history, or is path-dependent. Commitment to the notion of endogenous growth as path-dependent growth is evident in the work of the ,founding fathers of modern post-Keynesian macrodynamics. Hence for Kalecki:

"the long-run trend is but a slowly changing component of a chain of short-period situations; it has no independent identity, and the two basic relations mentioned above [the multiplier and the accelerator] should be formulated in such a way as to yield the trend cum business-cycle phenomenon." (Kalecki 1968: 263)

Meanwhile, according to Kaldor:

»it is impossible to assume the constancy of anything over time, such as the supply of labour or capital, the psychological preferences for commodities, the nature and number of commodities, or technical knowledge. All these things are in a continuous process of change but the forces that make for change are endogenous not exogenous to the system. The only truly exogenous factor is whatever exists at a given moment of time, as a heritage of the past." (Kaldor 1985: 61, emphasis in original)

Path-dependence in the growth process is also an important and recurring theme in the modern Kaleckian and Kaldorian growth theories that have grown out of the work of Rowthorn (I98I) and Dutt (I984), and Dixon and Thirlwall (I975) and Thirlwall (1979), respectively. Hence both Lavoie (1996) and Dutt (1997) explore the central importance of path dependence in the Kaleckian theory of growth and distribution, in which changes in the normal rate of capacity utilisation induced by changes in the actual capacity utilisation rate in the recent past have a central bearing on the character of the growth process. ${ }^{2}$ Meanwhile, Setterfield (1997b) and Roberts (200I and 2006) extend the scope of the path dependence central to Kaldorian theories of cumulative causation so as to allow for the possibility that an initially virtuous circle of self-reinforcing, rapid growth can endogenously induce structural changes that ultimately give rise to a vicious circle of slower growth.

\section{Exploring path dependence in contemporary post-Keynesian growth theory}

In order to demonstrate more precisely the role of path dependence in post-Keynesian growth theory, it is useful to address the question: What features of the growth process are understood to be path-dependent in post-Keynesian macrodynamics?

2 Specifically, they reconcile the achievement of a fully adjusted position « in which the equilibrium rate of capacity utilisation is equal to its normal rate with the 'paradox of costs ( the propensity of the rates of profit, growth and capacity utilisation to increase in response to a rise in the wage share of income), which requires variability in the long-run equilibrium rate of capacity utilisation. 


\section{I Path-dependence in the actual (equilibrium) rate of growth}

As has already been intimated, numerous post-Keynesian growth models posit path dependence in the actual (equilibrium) rate of growth. To explore this outcome further, we begin by considering a stylised, synthetic post-Keynesian growth model of the following form:

$$
\begin{aligned}
& y_{p} \equiv q+n, \\
& q=\bar{q}, \\
& n=\bar{n}, \\
& y=y(Z), \\
& Z=\bar{Z},
\end{aligned}
$$

where $y_{p}$ is the potential rate of growth, $q$ is the rate of growth of labour productivity, $n$ is the rate of population growth, ${ }^{3} y$ is the actual rate of growth, and $Z$ is a vector of variables that determines the level and/or rate of growth of aggregate demand. Substituting equations (2) and (3) into equation (1) yields:

$$
y_{p}=\bar{q}+\bar{n}
$$

while combination of equations (4) and (5) gives us:

$$
y=y(\bar{Z}) .
$$

Equations (6) and (7) describe the natural and actual (equilibrium) rates of growth, respectively. The former is universal to all post-Keynesian growth models, but the precise form taken by the latter varies between models. For example, in the canonical Kaleckian model of growth and distribution, the vector $Z$ reduces to the scalar $Z=\pi$, where $\pi$ is the profit share of income, and equation (7) becomes:

$$
y=\frac{s_{\pi} \pi \gamma}{\left(s_{\pi}-g_{r}\right) \pi-g_{u} v},
$$

where $s_{\pi}, \gamma, g_{r}, g_{u}$ and $v$ are constant coefficients associated with the explicit form of the function $y($.) in equation (4) representing (respectively) the propensity to save from profits, the rate of investment determined independently of the rates of profit and capacity utilisation, the sensitivity of investment to the profit rate, the sensitivity of investment to the capacity utilisation rate, and the full capacity capital-output ratio. In the canonical Kaldorian model of cumulative causation, meanwhile, we have, $Z^{T}=\left(y_{w} p_{w} w\right)$, where $y_{w}$ and $p_{w}$ are (respectively) the rates of growth of income and prices in the rest of the world and $w$ is the domestic rate of growth of nominal wages. The solution in (7) now appears as:

$$
y=\frac{\lambda \beta\left(p_{w}-w+r\right)+\gamma y_{w}}{1-\alpha \beta \lambda},
$$

3 The labour force participation rate is assumed constant, so that the rates of growth of population and of the labour force are equal. 
where $\lambda, \beta, r, \gamma$, and $\alpha$ are constant coefficients associated with the explicit form of the function $y($.) in equation (4) representing (respectively) the dynamic foreign trade multiplier, the price elasticity of demand for exports, the rate of growth of labour productivity independent of the growth of current output, the income elasticity of demand for exports and the sensitivity of labour productivity growth to the rate of growth of output (the so-called Verdoorn coefficient). The explicit functional forms in $(7 \mathrm{a})$ and $(7 \mathrm{~b})$ reflect differences between the canonical Kaleckian and Kaldorian models regarding the key source of autonomous demand and, consequently, the most important "drivers" of the expansion of aggregate demand. Hence in the Kaleckian approach, investment is the key source of autonomous demand, while the expansion of aggregate demand is also critically affected by the distribution of income. In Kaldorian models, meanwhile, exports are the key source of autonomous demand, and their rate of expansion (and hence the rate of growth of aggregate demand) is critically affected by technical change. Ultimately, however, these details recede before the common feature of both models - namely, that the rate of growth of output is demand-determined. It is this feature that justifies the claim to generality of the result in equation (7) derived from the synthetic post-Keynesian growth model presented above.

Turning our attention once again to equation (7) and the question of path dependence, introducing path dependence into the actual (equilibrium) rate of growth involves postulating that:

$$
\dot{Z}=Z(y-y(\bar{Z}))
$$

where $\bar{Z}$ is now understood to represent the instantaneous or temporary value of the exogenously given variables that help define the equilibrium solution to equations (4) and (5), and (correspondingly) $y(\bar{Z})$ represents the instantaneous or temporary value of the equilibrium solution itself, or what Chick and Caserta (1997) define as a 'provisional equilibrium $\triangleleft{ }^{4}$ According to equation (8), disequilibrium (a difference between the current and provisional equilibrium rate of growth) will revise the datar on which the provisional equilibrium growth rate is based, changing the value of this provisional equilibrium. Note that equation (8) may be linear and continuous (as in unit/zero root models of path dependence), in which case all history matters. That is, any difference between the current and provisional equilibrium rate of growth in equation (8) will (ceteris paribus) permanently affect the equilibrium growth rate. ${ }^{5}$ Alternatively, equation (8) may be non-linear, reflecting the importance of discontinuities encountered in the course of disequilibrium adjustments (as, for example, in strue hysteresis models of path dependence). In this case, only some departures

4 See also Setterfield (I997a) on the related notion of 'conditional equilibria', which are described as positions of equilibrium that "have been established by some prior path dependent process and await subsequent redefinition by forces endogenous to the sequential progression of the economy through historical time" (Setterfield, I997a: 84). According to Setterfield (1997a), conditional or provisional equilibria can also be re-defined by the cumulative experience of equilibrium conditions themselves. This possibility is, however, not captured in equation (8) and is not explored further in what follows. $5 \quad$ See Setterfield (2009) for more extensive discussion and analysis of the different types of path dependence identified here. 
of the current from the provisional equilibrium growth rate will create disequilibrium growth trajectories that influence the value of the provisional equilibrium rate of growth itself (i.e., only ssome history matters).

Another important distinction that equation (8) supports is that between positive and negative feedback from the current to the provisional equilibrium growth rate. Do we observe $Z^{\prime}>0$ (positive feedback) or $Z^{\prime}<0$ (negative feedback)? In fact, examples of both can be found in post-Keynesian macrodynamics. Hence the Kaleckian models of Lavoie (1995) and Dutt (1997) feature positive feedbacks. In these models, an increase in the growth rate raises capacity utilisation above its normal level, which increases the normal rate of capacity utilisation and hence the long-run equilibrium growth rate that is consistent with a ifully adjusted position (where the actual and normal rates of capacity utilisation are equal). In other words, faster growth in the short to medium term bequeaths faster long-run equilibrium growth, thanks to the positive influence of faster short to medium term growth on the value of alleged exogenous sdatar (in this case, the normal rate of capacity utilisation) and hence the long-run growth rate consistent with a fully adjusted position.

Meanwhile, in the Kaldorian models of Setterfield (1997 and 2002), negative feedback occurs. In these models, fast growth (growth in excess of the provisional equilibrium growth rate) causes the proliferation of technological interrelatedness, due to increases in the size of the capital stock embodying common technical standards of a certain vintage. This creates technological lock-in to capital that embodies these common technical standards, which eventually retards technical progress by diminishing the size of the Verdoorn coefficient (the ability of the economy to reap productivity gains induced by the expansion of aggregate output). The latter, in turn, reduces the long-run equilibrium growth rate. Hence faster growth in the short to medium term bequeaths slower long-run equilibrium growth, thanks to the negative influence of faster short- to medium-term growth on alleged exogenous sdatar (in this case, the Verdoorn coefficient) and hence the value of the long-run growth rate.

Whether it is continuous or discontinuous (i.e., whether all or only some history matters) and whether it features positive or negative feedbacks, the incorporation of equation (8) into post-Keynesian macrodynamic models - examples of which have been discussed briefly above - transforms the steady-state solutions of these models into provisional equilibria and renders their long-run outcomes path-dependent. This, in turn, makes post-Keynesian macrodynamic models broadly congruent with the important feature of historical time noted earlier - namely, that earlier states of the world affect later ones (including anything that can be construed as a ^long-run $`$ or , final $\prec$ outcome). The incorporation of path dependence also helps post-Keynesian models achieve greater congruence with the shifting equilibrium vision of macrodynamics identified by Kregel (1976) as the most appropriate direction in which post-Keynesian macrodynamics should seek to develop. 


\subsection{Path-dependence in the natural rate of growth}

The actual (equilibrium) rate of growth is not the only feature of the growth process that can be subject to path dependence. The natural rate of growth - which constrains the range of feasible values of the actual (equilibrium) growth rate in the long run and, as in equation (6), is usually thought of as an exogenously given growth sceiling - may also be endogenous in the sdeepers sense identified earlier (that is, sensitive to the actual growth path of the economy). A natural rate of growth that is path-dependent by virtue of its endogeneity to the actual rate of growth has long been postulated in post-Keynesian macrodynamics (see, for example, Cornwall 1972 and 1977), and more recently has been empirically verified in the work of León-Ledesma and Thirwall (2000 and 2002).

Capturing path dependence in the natural rate of growth in the synthetic post-Keynesian growth model introduced above involves one simple amendment to this model. Specifically, we need only replace equation (2) with:

$$
q=q(y),
$$

where equation (9) represents a simplified Verdoorn law, according to which technical progress (measured by the rate of growth of labour productivity) varies directly with the rate of growth of actual output, thanks to the existence of dynamic increasing returns. ${ }^{6}$ Solving the model in equations (1), (3) - (5) and (9) once again yields two distinct growth rates. First, and as before, combination of equations (4) and (5) yields:

$$
y=y(\bar{Z}),
$$

where, it should be remembered, in the presence of equation (8), the resulting solution constitutes a provisional equilibrium rate of growth. Meanwhile, substituting equations (3) and (9) into equation (1), and also taking into account equation (7) above, we arrive at:

$$
y_{p}=q(y(\bar{Z}))+\bar{n} .
$$

Equation (10) describes the natural rate of growth in the presence of the Verdoorn law, and makes clear the sense in which the economy's growth sceiling is no longer exogenous. Specifically, equation (10) states that the natural rate of growth will vary with the actual (equilibrium) rate of growth, and is therefore path-dependent in the sense that a different historical growth experience will result in a different natural rate of growth - i.e., a different upper bound on the feasible rate of growth that the economy can achieve in the long run. Note also that, as described in equation (10), this path dependence of the natural rate of growth involves strictly positive feedback: an increase (decrease) in the equilibrium rate of growth will relax (tighten) the constraint on long-run growth imposed by the natural rate by raising (lowering) the value of the latter. 


\subsection{A potential problem}

The results above reveal that, even with an endogenous natural rate, the synthetic postKeynesian growth model will, in general, encounter the first Harrod problem (inequality of the equilibrium and natural rates of growth). In order to avoid this problem, we need to observe $y=y_{p}$ or in other words, from equations (7) and (10):

$$
y(\bar{Z})=q(y(\bar{Z}))+\bar{n} .
$$

The equality in (11) is possible, but not likely. To see why, suppose we give the Verdoorn law in (9) the explicit functional form:

$$
q=\kappa+\delta y \text {. }
$$

Substituting (7) into (9a) yields:

$$
q=\kappa+\delta[y(\bar{Z})] .
$$

Combining (11) and (12) suggests that, in order to avoid the first Harrod problem, we must have:

$$
\begin{aligned}
& y(\bar{Z})=\kappa+\delta[(y(\bar{Z})]+\bar{n} \\
& \Rightarrow y(\bar{Z})=\frac{\kappa+\bar{n}}{1-\delta}
\end{aligned}
$$

Since $\bar{Z}, \kappa, \delta$, and $\bar{n}$ are all exogenously given independently of one another, this amounts to an unlikely, special case.

Unfortunately, failure to observe the equality in (11) can be problematic in the context of a steady state growth model. Hence define:

$$
E=\frac{Y}{Y_{p}}
$$

where $Y$ and $Y_{p}$ are the levels of actual and potential real output, respectively. The variable $E$ thus measures the extent to which the economy is fully utilising its productive resources at any point in time. ${ }^{7}$ It follows from the definition of $E$ that:

$$
\dot{E}=E\left(y-y_{p}\right) .
$$

7 It is straightforward to show that $E$ measures the employment rate. Hence note that it follows from the definition of $E$ above that: $E=\frac{\frac{Y}{N}}{\frac{Y_{p}}{L} \frac{L}{N}}$, where $N$ is the level of employment and $L$ is the size of the labour force. Defining $a$ as the labour-output ratio implied, at any point in time, by a fixedcoefficient production technology characterising the supply side of the economy, we have $\frac{Y}{N}=\frac{Y_{p}}{L}=\frac{1}{a}$. Substituting into the expression for $\mathrm{E}$ above and simplifying, we arrive at: $E=\frac{N}{L}$. 
Now note that if (11) does not hold so that $y \neq y_{p}$, equation (14) implies that $\dot{E}=c \neq 0$, where $c$ is some constant. But since the variable $E$ is bounded above and below such that $0 \leq E \leq 1$, it is not possible to have a constant, non-zero rate of change of $E$ in the long run. In other words, $y \neq y_{p}$ is not sustainable as a steady-state outcome: it will eventually violate the requirement that $0 \leq E \leq 1$. But unfortunately, as demonstrated above, $y=y_{p}$ is not likely in the synthetic post-Keynesian model developed thus far. ${ }^{8}$

\subsection{Path dependence as the solution}

The problem identified above can be resolved by appeal to additional path dependence in the growth process. Suppose, for example, that we further modify our synthetic post-Keynesian growth model by replacing equation (9) with: ${ }^{9}$

$$
q=q(y, E), \quad q_{E}>0
$$

In equation (9b), both the rate of growth $(y)$ and the level of output $(Y)$ influence technical change. ${ }^{\text {Io }}$ The rationale for the equation is as follows: As the value of $E$ rises, the goods market tightens, as actual real output moves closer to its supply-determined limit. This tightening of the goods market, in turn, encourages firms to engage in more innovation and technical change for any given value of $y$. In other words, the growth-induced technical change associated with the Verdoorn law will be more in evidence when the level of activity (relative to potential) is higher and when there are, by extension, fewer idle resources that can be used to accommodate the current rate of expansion if it extends into the future.

Solving the model in equations (1), (3) - (5) and (9b) yields the now-familiar result of two distinct growth rates. Once again, combination of equations (4) and (5) yields:

$$
y=y(\bar{Z})
$$

where, once again, the presence of equation (8) implies that this solution constitutes a provisional equilibrium rate of growth. But substituting equations (3) and (9b) into equation (1) and taking into account the result in (7) now yields:

$$
y_{p}=q(y(\bar{Z}), E)+\bar{n} .
$$

Moreover, we also have:

$$
\dot{E}=E\left(y-y_{p}\right) \text {. }
$$

8 Of course, the prospect of path-dependent revision of the provisional equilibrium $y(\bar{Z})$ may, in practice, render moot the issue of the sustainability of any particular provisional equilibrium growth rate. But with advanced capitalist economies having displayed a proclivity to operate at or close to full employment for at least one extended period during the twentieth century (the post-war Golden Age), it is not obvious that such raccidental change in the provisional equilibrium rate of growth can always be relied upon to foil problems associated with the un-sustainability of the growth rate.

9 The model that results from this modification resembles that of Setterfield (2006). See also Palley (2002) for a similar model.

Io Recall that $E=Y / Y_{p}$, so that $E$ (and hence $q$ in equation [9b]) is increasing in $Y$. 
Figure I: Adjustment of the natural rate towards the actual rate of growth

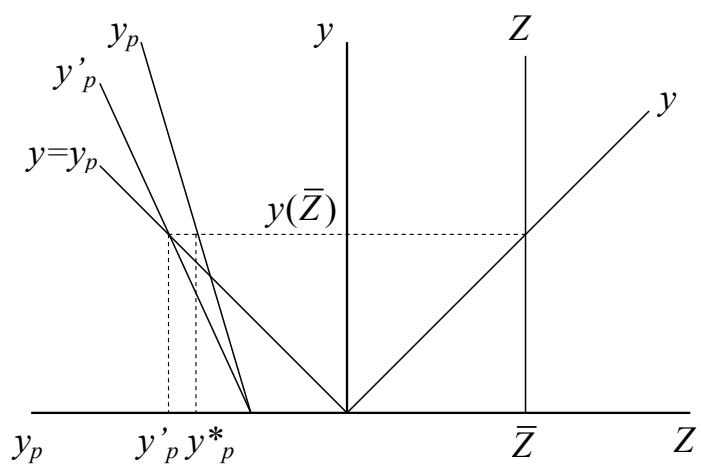

The workings of the model are described by the dynamical interaction of equations (7), (14), and (15), as illustrated in Figure I. Assume, then, that we begin with the provisional equilibrium growth rate $y(\bar{Z})$ determined in the right-hand panel of Figure I. Initially, this gives rise to the endogenous natural rate $y_{p}^{*}$, as shown in the left-hand panel of the Figure. But it is clear from the $y=y_{p}$ schedule that $y_{p}^{*}<y(\bar{Z})=y_{p}^{\prime}$. According to equation (14), we will therefore observe $\dot{E}>0$, as a result of which the rate of growth of productivity and hence the natural rate of growth itself will begin to rise, even as the actual (provisional equilibrium) rate of growth remains unchanged. ${ }^{\text {II }}$ This is captured in Figure $\mathrm{I}$ by the rotation of the $y_{p}$ schedule to the left. The adjustments so-described will continue until the schedule describing the determination of the natural rate of growth reaches $y_{p}^{\prime}$. At this point, we will observe $y(\bar{Z})=y_{p}^{\prime}$ (as shown in the left-hand panel of Figure I) and the model will have reached a ifully-adjusted provisional equilibrium, where both $y=y(\bar{Z})$ and $y=y_{p}$. Solving equations (7), (14) and (15) for $y=y_{p}$, this fully-adjusted provisional equilibrium can be described as:

$$
q\left(y(\bar{Z}), E^{*}\right)+\bar{n}=y(\bar{Z}),
$$

where $E^{*}$ is the provisional equilibrium value of $E .^{\text {I2 }}$ By virtue of the fact that it removes the first Harrod problem from our description of the growth process, equation (16) now describes a sustainable steady-state outcome.

II Note that if the provisional equilibrium growth rate is also sensitive to determinants of the rate of productivity growth - as in the Kaldorian model outlined in Section 3-then the actual (equilibrium) as well as the natural rate of growth will be influenced by the adjustment mechanism in (14). See Setterfield (20IO) for explicit discussion of this possibility.

I2 Note that the precise equilibrium value of $E$ is indeterminate. We do, however, know that $0 \leq E^{*} \leq 1$ which, in turn, implies that there are limits (imposed by the boundedness of $E$ ) to the adjustment process described above. These limits are analogous to those associated with Kaldor's (I959) 


\section{Recent developments in neoclassical endogenous growth theory}

As has been demonstrated above, post-Keynesian macrodynamics is steeped in the notions that growth is both demand-led and path-dependent. Nevertheless, it is well for postKeynesians to be aware of some recent developments in neoclassical endogenous growth (NEG) theory that encroach on this terrain.

The rudiments of NEG theory can be summarised by the following model:

$$
\begin{aligned}
& y_{p} \equiv q+n, \\
& n=\bar{n}, \\
& y=y_{p}, \\
& q=q(X), \\
& X=\bar{X},
\end{aligned}
$$

where equation (17) is now understood causally (the potential rate of growth determines the actual rate of growth), and equation (18) is a technical progress function in which $X$ is a vector of variables that affect the resources devoted to and/or the incentives to produce technological change. Solving the model in equations (1), (3), (17), (18) and (19) yields the following solution for the actual (equilibrium) rate of growth:

$$
y=q(\bar{X})+\bar{n} .
$$

This is, of course, identical to the expression for the potential rate of growth (by virtue of equation [17]) so that, unlike the synthetic post-Keynesian model developed earlier, there is no possibility of observing the first Harrod problem. One example of an NEG model is the so-called $` A K$ ' model. ${ }^{13}$ In this model the vector $Z$ again reduces to a scalar, $Z=s$, where $s$ denotes the saving rate. The latter (in conjunction with the capital to output ratio and the rate of growth of the labour force) determines the rate of growth of the capital to labour ratio and hence the rate of growth of output per worker. The expression in (20) becomes:

$$
y=s A,
$$

where $A$ denotes the output to capital ratio.

The AK model and the canonical Kaleckian model described earlier facilitate ready comparison of and contrast between the NEG and post-Keynesian traditions in growth theory. ${ }^{14}$ Hence note that it follows from (20a) that:

model, in which the actual (equilibrium) and natural rates of growth are reconciled through variations in the functional distribution of income.

I3 See, for example, Aghion and Howitt (2009: I3-I8) on this and other variants of NEG theory. I4 The AK model bears closer resemblance to the Kaleckian than the Kaldorian model because the former, like the AK model, theorises growth in a closed economy with no active government sector, and is therefore centered on the relationship between investment and saving. As discussed earlier, 


$$
\frac{\partial y}{\partial s}=A>0,
$$

while equation $(7 \mathrm{a})$ yields:

$$
\frac{\partial y}{\partial s_{\pi}}=\frac{-\gamma \pi\left(g_{r} \pi+g_{u} v\right)}{\left[\left(s_{\pi}-g_{r}\right) \pi-g_{u} v\right]^{2}}<0 .
$$

These derivatives demonstrate a fundamental distinction between NEG and post-Keynesian growth theory as regards the acceptance (as in post-Keynesian theory) or denial (as in NEG theory) of the long-run applicability of the paradox of thrift. This is, perhaps, hardly surprising given the supply-side pedigree of all neoclassical growth theory. And yet as intimated above, recent developments in NEG theory encroach on the terrain of postKeynesian macrodynamics, by suggesting that long run growth can be both influenced by demand and (in the process) be path dependent.

The neoclassical developments alluded to here are associated with the work of Aghion and Howitt (1992) and Martin and Rogers (1997). Hence suppose that we modify the sbaseline NEG model in equations (1), (3) and (17) - (19) by replacing equation (17) and (19) (respectively) with:

$$
\begin{aligned}
& y=y_{p}+\varepsilon, \\
& \dot{X}=h\left(y-y_{p}\right), \quad h^{\prime}>0,
\end{aligned}
$$

where $\varepsilon=\alpha \varepsilon_{-1}+\eta$ (with $0<\alpha<1$ and $\eta \sim\left(0, \sigma_{\eta}^{2}\right)$ ) describes a persistent shock to growth. Equation (21) allows for (persistent) departures of the actual rate of growth from the natural rate caused by exogenous shocks. Equation (22), meanwhile, suggests that these departures of the actual from the natural rate of growth will induce changes in the determinants of the rate of productivity growth, where $h^{\prime}>0$ allows for the possibility that technical change may be stimulated in this fashion by either disturbances that raise the actual rate of growth above the natural rate (as in the learning by doing model of Martin and Rogers [1997]) or disturbances that reduce the actual rate of growth below the natural rate (as in the creative destruction model of Aghion and Howitt [1992]).

In order to solve the extended NEG model in equations (1), (3), (18), (21) and (22) for the steady state rate of growth, we begin by setting $\varepsilon=0$. This ensures that $y=y_{p}$ in equation (21), and hence that $\dot{X}=0$ in equation (22). Finally, combining this information with equations (1), (3) and (18) yields:

$$
y=q\left(X^{*}\right)+\bar{n}
$$

where $X^{*}$ denotes the (indeterminate) steady state equilibrium value of $X$.

international trade is central to the Kaldorian model, which is therefore more closely comparable to variants of NEG theory that also emphasise the importance of trade (see, for example, Grossman/ Helpman [I99I]). 
The result in (23) is clearly analogous to the solution of the baseline NEG model found in equation (20). Note, however, that in the extended model, any random shock $\eta \neq 0$ will give rise to a value of $\varepsilon \neq 0$ for several successive periods (the duration of this last result varying directly with the size of $\alpha$ ). This event simulates the possibility of trade cycle disturbances temporarily dislodging the actual rate of growth from its natural rate. But note that these disturbances are not neutral with respect to the long-run growth performance of the economy. On the contrary, with $\varepsilon \neq 0$, we will observe $y \neq y_{p}$ in equation (21) and hence $\dot{X} \neq 0$ in equation (22). This last event will change the rate of growth of productivity in equation (18) and hence the value of the natural rate of growth (which is found from combination of equations (1), (3) and (18)). These adjustment dynamics will continue until we arrive at a new steady state equilibrium (characterised by $\varepsilon=0$ and hence $y=y_{p}$ and hence $\dot{X}=0$ ), which can be written as:

$$
y=q\left(X^{\prime}\right)+\bar{n},
$$

where $X^{\prime} \neq X^{*}$ represents the new steady state equilibrium value of $X$, with $X^{\prime}-X^{*}$ capturing the cumulative impact of cyclical departure from the steady state growth path on the determinants of technical progress. It is clear from (23) that the temporary departure of the actual rate of growth from the steady state value with which we began has induced changes in the longrun steady state rate of growth itself. In other words, both the actual (equilibrium) and natural rates of growth display path dependence. ${ }^{\text {I5 }}$ Moreover, if $\varepsilon$ is interpreted as capturing persistent demand shocks (due to the presence of nominal rigidities, for example), then the path-dependent actual and natural rates of growth that result from this extended NEG model are also demand-determined.

It is certainly not common to find terms like 'path-dependent growth', ,demandled growth or sendogenous natural rate in NEG theory. But the fact remains that, as demonstrated above, some NEG models now feature all of these attributes. It is also important to recall the fundamental differences that separate post-Keynesian macrodynamic models from even the specific class of NEG models characterised by equations (1), (3), (18), (21), and (22) ${ }^{16}$ Nevertheless, the results presented in this section are suggestive of a certain degree of observational equivalence as between (some) NEG models and post-Keynesian macrodynamics.

I5 Recall that, with $\varepsilon=0$, we have $y=y_{p}$ from equation (21).

I6 These include: a) the basic nature of the relationship between saving and growth (as reflected in the signs of the derivatives of growth with respect to the saving rate); b) the strictly positive feedback from $y$ to $y_{p}$ in post-Keynesian macrodynamics (resulting from the Verdoorn law) versus the positive or negative feedback that can arise in NEG models (depending on the precise characterisation of technical change); and c) the fact that equilibrium as well as disequilibrium experience can, in principle, result in the endogenous revision of a position of equilibrium in post-Keynesian macrodynamics (as previously intimated in footnote 4). 


\section{Opportunities and challenges for post-Keynesians}

The obvious question to raise in response to the conclusion reached at the end of the previous section is: so what? The purpose of this section is to reflect on some of the possible pros and cons for post-Keynesian macrodynamics of what was described above as the encroachment of neoclassical growth theory into the traditional post-Keynesian terrain of demand-determined, path-dependent growth.

\section{I Opportunities for post-Keynesians}

The results reported in the previous section suggest that over the last two decades, there has been a certain degree of theoretical convergence between NEG theory and post-Keynesian macrodynamics. While it would be an exaggeration to claim that we are all advocates of demand-determined, path-dependent growth now , it could be argued that demanddetermined, path-dependent growth is an emerging scommon front in growth theory, that unites otherwise quite different approaches to macrodynamic analysis. In principle, this common front could provide a basis for greater dialogue between post-Keynesian and neoclassical growth theorists, and even cross-fertilisation of models to the extent that some (albeit not all) of the >mechanics of growth outlined in the models developed in Sections 3 and 4 are compatible with both post-Keynesian and neoclassical visions of the growth process. The possibilities for such cross-fertilisation are already exemplified in the work of Dutt (2006 and 2010), whose hybrid model combines a Classical technical progress function (based on induced, factor biased technical change) with a neoclassical growth model to produce Keynesian (demand-determined) long-run growth outcomes.

\subsection{Challenges for post-Keynesians ${ }^{17}$}

It is possible, however, that rather than generating more dialogue and a common research interest, the degree of theoretical convergence between NEG theory and post-Keynesian macrodynamics noted in Section 4 will be thoroughly disadvantageous to the post-Keynesian tradition. One reason for this concerns control over the rhetoric of growth theory. It was noted earlier that neoclassical economists have already captured the terminology of growth theory, certainly insofar as it relates to the concept of endogenous growth', which is associated exclusively with recent developments in neoclassical growth theory. ${ }^{18}$ They can also be said to have captured the history of growth theory, which in undergraduate textbooks is now commonly presented as a simple march of progress from first generation neoclassical growth theory (associated with the Solow model) to second generation neoclassical growth theory associated with NEG models (Setterfield 2002 and 2003). This control of the rhetoric of

I8 Once again, the interested reader is referred to Roberts and Setterfield (2007) on this theme. 
growth theory may lack intellectual substance, but insofar as it results (either intentionally or unintentionally) in the exclusion of post-Keynesian macrodynamics from discussion of the growth process, it is real and therefore important in practice. Specifically, it suggests that, rather than providing a basis for dialogue and interaction, the developments described in the preceding section are more likely to give rise to $\mathrm{a}$ D Duncan Foley moment ${ }^{19}$ : a situation where, having previously been told that their results concerning the possibility of demandled, path-dependent growth are uninteresting, post-Keynesians will now be told that the mainstream salready knows about these possibilities - thus rendering post-Keynesian macrodynamics redundant.

A second (related) problem concerns the old adage that it takes two to tango $<-$ or, in this case, to have a conversation. Put bluntly, are neoclassical growth theorists interested in dialogue with post-Keynesians, regardless of the opportunities for dialogue that now seemingly exist? The evidence is not encouraging. Hence while post-Keynesian macrodynamics is replete with references to the neoclassical literature (see, for example, Setterfield [2002 and 2003], Dutt [2006 and 2010], and Leon-Ledesma and Lanzafame [2010] on NEG models in which demand influences growth), this attention appears to be asymmetric: the recent contributions to NEG theory discussed in the previous section do not refer to similar and earlier results in post-Keynesian macrodynamics. This is, perhaps, not altogether surprising. After all, why should neoclassical economists want to talk to post-Keynesians? Simply put, it is not in the self-interest of a majority view to seek out dissent if the latter could threaten the majority's current position of privilege (as reckoned in terms of prestige, access to and control over resources, and so forth).

\section{Conclusions}

The primary purpose of this paper has been to discuss the long - and ongoing - association between post-Keynesian macrodynamics and the notion of path-dependent growth. It has been shown that path dependence can be postulated in both the actual (equilibrium) rate of growth and the natural rate of growth that provides an upper bound to the growth rate in the long run. Path dependence also provides plausible and useful ways of resolving the first Harrod problem (concerning inequality of the equilibrium and natural rates of growth) that typically characterises post-Keynesian growth models, without resorting to the neoclassical approach of ruling out this problem by describing growth as an innately supply-led process.

It has also been shown, however, that traditional post-Keynesian themes - including not just path dependence, but also the notion that demand has a role to play in the determination of long-run growth - can now be found in neoclassical endogenous growth (NEG) theory. Normally, this development might create opportunities for increased dialogue between erstwhile competing research traditions, to the potential benefit of both. However, economics

I9 I am grateful to Duncan Foley for relating to me his career-long experience of these >moments in a private conversation in February 2009. 
has questionable claims to 'normality in this sense. If the obstacles to dialogue between the neoclassical and post-Keynesian traditions in growth theory that have been identified in this paper dominate, then the recent encroachment of NEG theory onto traditional post-Keynesian terrain may prove perilous rather than advantageous. In this particular case, then, and contrary to the advice of those who recommend greater post-Keynesian involvement in and incorporation into what they identify as a currently more open-minded mainstream, ${ }^{20}$ it may be important for those interested in the further development of postKeynesian macrodynamics to continue to engage in the sort of institution building that Palley (I996, ch.3) identifies as essential for the survival of a school of thought. The alternative may be that ideas previously unique to post-Keynesian macrodynamics will be re-packaged as srecent neoclassical discoveries and hence as further evidence that post-Keynesian growth theory has nothing to contribute.

\section{References}

Aghion, P., Howitt, P. (1992): A model of growth through creative destruction, in: Econometrica, 60, 323-5I.

Aghion, P., Howitt, P. (2009): The Economics of Growth, Cambridge, MA: MIT Press.

Blecker, R. (2002): Distribution, demand and growth in neo-Kaleckian macro models, in: Setterfield, M. (ed.), The Economics of Demand-Led Growth: Challenging the Supply-Side Vision of the Long Run, Cheltenham: Edward Elgar, $129-52$.

Chick, V., Caserta, M. (1997): Provisional equilibrium in macroeconomic theory, in: Arestis, P., Palma, G., Sawyer, M. (eds.), Markets, Unemployment and Economic policy: Essays in Honour of Geoff Harcourt, Volume Two, London: Routledge, 223-37.

Colander, D., Holt, R.P.F., Rosser, J.B. (2004a): The Changing Face of Economics: Conversations with Cutting Edge Economists, Cheltenham: Edward Elgar.

Colander, D., Holt, R.P.F., Rosser, J.B. (2004b): The changing face of mainstream economics, in: Review of Political Economy, 16, 485-99.

Dixon, R., Thirlwall, A.P. (1975): A model of regional growth rate differences along Kaldorian lines, in: Oxford Economic Papers, 27, 20I-I4.

Dutt, A.K. (1984): Stagnation, income distribution, and monopoly power, in: Cambridge Journal of Economics, 8, 25-40.

Dutt, A.K. (1997): Equilibrium, path dependence and hysteresis in post-Keynesian models, in: Arestis, P., Palma, G., Sawyer, M. (eds.), Essays In Honour Of Geoff Harcourt. Volume 2. Markets, Unemployment And Economic Policy, London: Routledge, 238-53.

Dutt, A.K. (2006): Aggregate demand, aggregate supply and economic growth, in: International Review of Applied Economics, 20, 319-36.

Dutt, A.K. (20IO): Reconciling the growth of aggregate demand and aggregate supply, in: Setterfield, M. (ed.), Handbook of Alternative Theories of Economic Growth, Cheltenham: Edward Elgar, 220-40. 
Grossman, G.M., Helpman, E. (1991): Innovation and Growth in the GlobalEconomy, Cambridge, MA: MIT Press.

Jones, C.I. (2002): Introduction to Economic Growth, Second Edition, New York: W.W. Norton. Kaldor, N. (1959): Economic growth and the problem of inflation, in: Economica, 26, 212-26. Kaldor, N. (1985): Economics Without Equilibrium, Cardiff: University College Cardiff Press. Kalecki, M. (1968): Trend and business cycle reconsidered, in: Economic Journal, 78, 263-76. Lavoie, M. (1992): Foundations of Post-Keynesian Economic Analysis, Aldershot: Edward Elgar.

Lavoie, M. (1996): Traverse, hysteresis, and normal rates of capacity utilization in Kaleckian models of growth and distribution, in: Review of Radical Political Economics, 28, $113-47$.

León-Ledesma, M., Thirlwall, A.P. (2000): Is the natural rate of growth exogenous, Banca Nazionale Del Lavoro Quarterly Review, 215, 433-445.

León-Ledesma, M.A., Thirlwall, A.P. (2002): The endogeneity of the natural rate of growth, in: Cambridge Journal of Economics, 26, 44I-59.

León-Ledesma, M., Lanzafame, M. (20I0): The endogenous nature of the "natural " rate of growth, in: Setterfield, M. (ed.), Handbook of Alternative Theories of Economic Growth, Cheltenham: Edward Elgar, 208-i9.

Lucas, R.E. (1988): On the mechanics of economic development, in: Journal of Monetary Economics, 22, 3-42.

Martin, P., Rogers, C.A. (1997): Stabilization policy, learning by doing and economic growth, in: Oxford Review of Economic Policy, 49, 152-66.

McCombie, J.S.L., Thirlwall, A.P. (1994): Economic Growth and the Balance-of-Payments Constraint, London: Macmillan.

McCombie, J.S.L., Pugno, M., Soro, B. (eds.) (2003): Productivity Growth and Economic Performance: Essays on Verdoorn's Law, London: Palgrave Macmillan.

Palley, T.I. (1996): Post Keynesian Economics, London: Macmillan.

Palley, T.I. (2002): Pitfalls in the theory of growth: an application to the balance-of paymentsconstrained growth model, in: Setterfield, M. (ed.), The Economics of Demand-Led Growth: Challenging the Supply-Side Vision of the Long Run, Cheltenham: Edward Elgar, II $5-25$.

Roberts, M. (200I): Endogenous structural change, in: Zagreb International Review of Economics and Business, 4, I-22.

Roberts, M. (2006): Modelling historical growth: A contribution to the debate, in: Arestis, P., McCombie, J., Vickerman, R. (eds.), Growth and Economic Development: Essays in Honour of A.P. Thirlwall, Cheltenham: Edward Elgar, 96-II5.

Roberts, M., Setterfield, M. (2007): What is endogenous growth theory?, in: Arestis, P., Baddeley, M., McCombie, J.S.L. (eds.), Economic growth: New Directions in Theory and Policy, Cheltenham: Edward Elgar, I4-3і.

Romer, P.M. (1986): Increasing returns and long-run growth, in: Journal of Political Economy, 94, $1002-37$.

Romer, P.M. (1990): Endogenous technological change, in: Journal of Political Economy, 98, 7I-IO3. 
Rowthorn, R.E. (198I): Demand, real wages and economic growth, in: Thames Papers in Political Economy, London: Thames Polytechnic.

Setterfield, M. (1997a): Rapid Growth and Relative Decline: Modelling Macroeconomic Dynamics with Hysteresis, London: Palgrave.

Setterfield, M. (1997b): ‘History versus equilibrium` and the theory of economic growth, in: Cambridge Journal of Economics, 2I, 365-78.

Setterfield, M. (2002): Introduction: A dissenter's view of the development of growth theory and the importance of demand-led growth, in: Setterfield, M. (ed.), The Economics of Demand-Led Growth: Challenging the Supply-Side Vision of the Long Run, Cheltenham: Edward Elgar, I-I6.

Setterfield, M. (2003): Supply and demand in the theory of long-run growth: Introduction to a symposium on demand-led growth, in: Review of Political Economy, I5, 23-32.

Setterfield, M. (2006): Thirlwall's Law and Palley's Pitfalls: A reconsideration, in: Arestis, P., McCombie, J., Vickerman, R. (eds.), Growth and Economic Development: Essays in Honour of A.P. Thirlwall, Cheltenham: Edward Elgar, 47-59.

Setterfield, M. (2009): Path dependency, hysteresis and macrodynamics, in: Arestis, P., Sawyer, M. (eds.), Path Dependency and Macroeconomics (International Papers in Political Economy 2009), London: Palgrave Macmillan, 37-79.

Setterfield, M. (2009b): Neoclassical growth theory and heterodox growth theory: Opportunities for and obstacles to greater engagement, Trinity College Department Of Economics, Working Paper 09-oI.

Setterfield, M. (20IO): Endogenous growth: A Kaldorian approach, Trinity College Department of Economics, Working Paper Io-oI.

Thirlwall, A.P. (1979): The balance of payments constraint as an explanation of international growth rate differences, in: Banca Nazionale del Lavoro Quarterly Review, I28, 45-53. 